\title{
Acute Respiratory Failure in a Child after Talc Inhalation
}

\author{
Federica Patarino ${ }^{\mathrm{a}}$ Stefania Norbedo ${ }^{\mathrm{a}}$ Egidio Barbi ${ }^{\mathrm{a}}$ Furio Poli ${ }^{\mathrm{a}}$ \\ Stefano Furlan ${ }^{b}$ Fabio Savron ${ }^{b}$

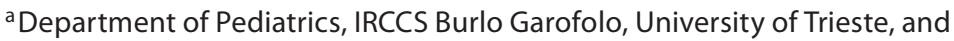 \\ ${ }^{b}$ Department of Anaesthesia and Intensive Care, IRCCS Istituto per I'Infanzia \\ Burlo Garofolo, Trieste, Italy
}

A 19-month-old patient was admitted for a 2-day history of worsening cough and dyspnea which required intubation. On examination, she was afebrile, with 60 breaths per minute, suprasternal indrawings, an oxygen saturation of $70 \%$, and decreased breath sounds over the left hemithorax.

A chest radiograph showed complete left opacity with mediastinal shift. A high-resolution CT scan of the chest (fig. 1) showed left opacity with right lung hyperinflation and mediastinal shift.

No history of acute inhalation was reported, but further questioning revealed that the patient had played with a talc dispenser 2 days before (fig. 2).

A bronchoscopy was performed without evidence of mucus plugs. Bronchoalveolar lavages (BALs) showed large amounts of viscous, whitish secretions. BAL stain examination showed talc crystals, while cultures were negative both for bacteria and virus. An intravenous treatment with antibiotics and steroids was empirically started and the patient was extubated after 2 days.

Talc inhalation occurs in children around 1 year of age, mostly while babies are being changed and have easy access to the powder [1]. It can lead to severe bronchiolar obstruction and massive bronchiolitis. The treatment is supportive.

We believe that in our case the shape of the talc device ('bottle like') and the 'roller' releasing system, which delivers large amounts of substance, played a major role. The unilateral involvement is peculiar and difficult to explain even if solid foreign body inhalation is reported in the left lung in $50 \%$ of cases [2]. Unfortunately, BAL was not analyzed separately from the main bronchi in order to prove a much higher content of talc in the left side, even though the diagnosis of talc inhalation is supported by the massive presence of crystals in the BAL stain, by the delay between the inhalation and the respiratory failure and by the lack of evidence of mucus plug or infection.

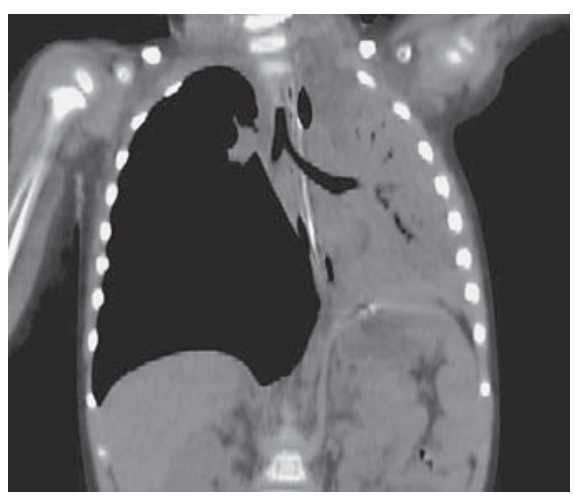

Fig. 1. High-resolution CT scan of the chest.

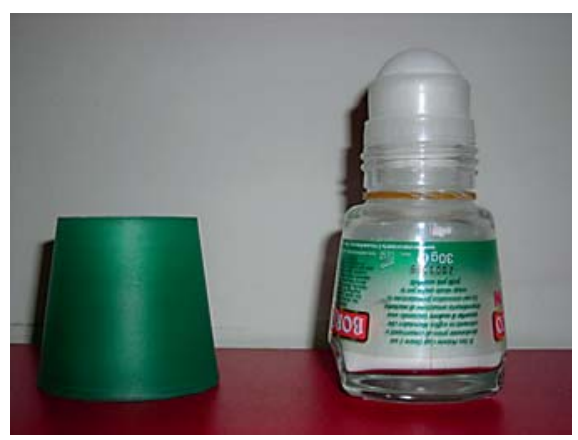

Fig. 2. Talc dispenser.

References

1 Mofenson HC, Greensher J, DiTomasso A, Okun S: Baby powder - a hazard! Pediatrics 1981;68:265-266.

-2 Van Looij MA, Rood PP, Hoeve LJ, Borgstein JA: Aspirated foreign bodies in children: why are they more commonly found on the left? Clin Otolaryngol Allied Sci 2003;28:364367.

\section{KARGER}

Fax +41613061234 E-Mail karger@karger.ch www.karger.com
(C) 2008 S. Karger AG, Base 0025-7931/10/0794-0340\$26.00/0
Federica Patarino

University of Trieste, IRCCS Burlo Garofolo, Department of Pediatrics

Via dell' Istria, 65/1

IT-34100 Trieste (Italy)

Tel. +39 040378 5312, Fax +39040 378 5452, E-Mail fpatarino@yahoo.it 